\title{
Corrigendum to "Cerium Oxide Nanoparticles Induced Toxicity in Human Lung Cells: Role of ROS Mediated DNA Damage and Apoptosis"
}

\author{
Sandeep Mittal $\mathbb{D}^{1,2}$ and Alok K. Pandey $\mathbb{D i D}^{1,2}$ \\ ${ }^{1}$ Academy of Scientific and Innovative Research (AcSIR), New Delhi 110025, India \\ ${ }^{2}$ Nanomaterial Toxicology Group, CSIR-Indian Institute of Toxicology Research (CSIR-IITR), P.O. Box 80, Mahatma Gandhi Marg, \\ Lucknow, Uttar Pradesh 226001, India
}

Correspondence should be addressed to Alok K. Pandey; pandeyalok2006@gmail.com

Received 9 October 2018; Accepted 21 October 2018; Published 16 December 2018

Copyright (c) 2018 Sandeep Mittal and Alok K. Pandey. This is an open access article distributed under the Creative Commons Attribution License, which permits unrestricted use, distribution, and reproduction in any medium, provided the original work is properly cited.

In the article titled "Cerium Oxide Nanoparticles Induced Toxicity in Human Lung Cells: Role of ROS Mediated DNA Damage and Apoptosis" [1], there was figure duplication in Figure 9(c), where the second panel, Cleaved PARP, is similar to the fourth one, Phosopho p53. Figure 9 including the revised image for panel four, Phosopho p53, is shown below and the original figures are added as supplementary materials (available here).

\section{Supplementary Materials}

The original uncropped and unadjusted Western Blots for all the panels in Figure 9a, 9b, and 9c. (Supplementary Materials) 


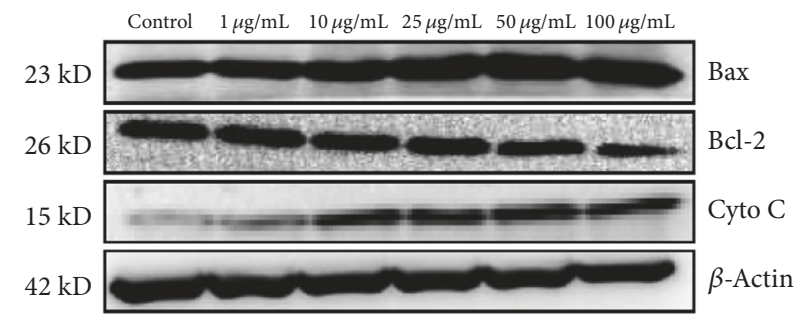

(A)

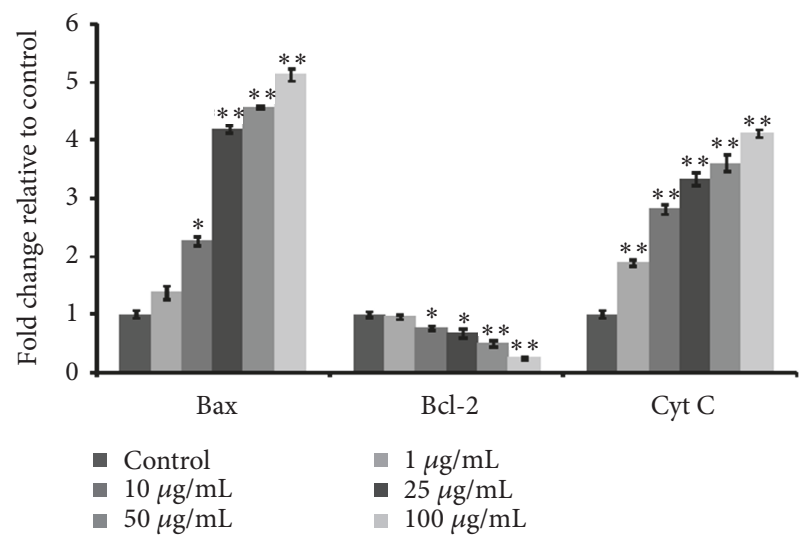

(Aa)

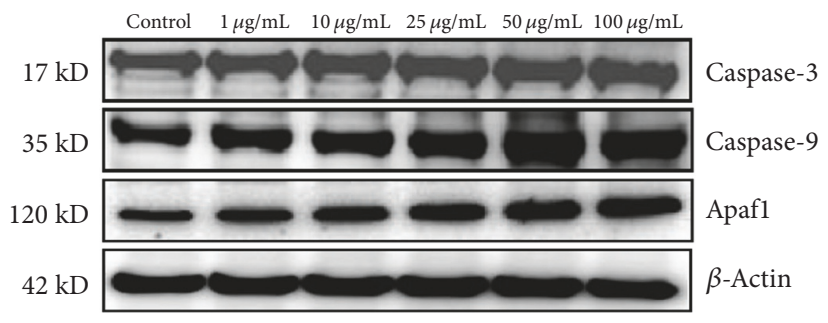

(B)

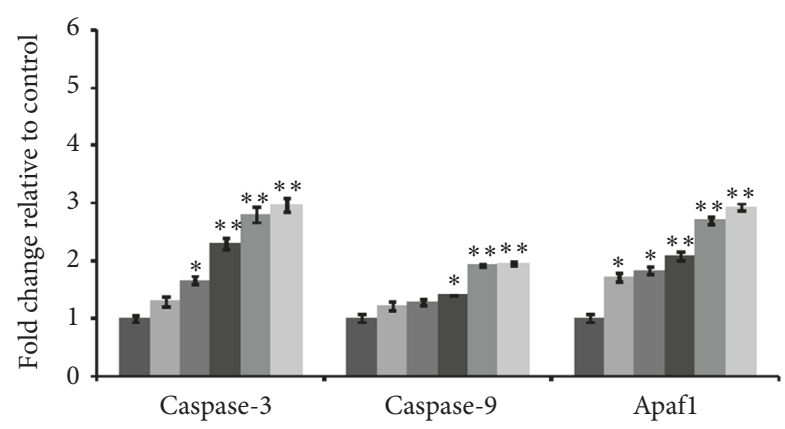

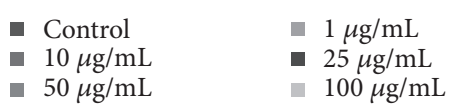

(Bb)

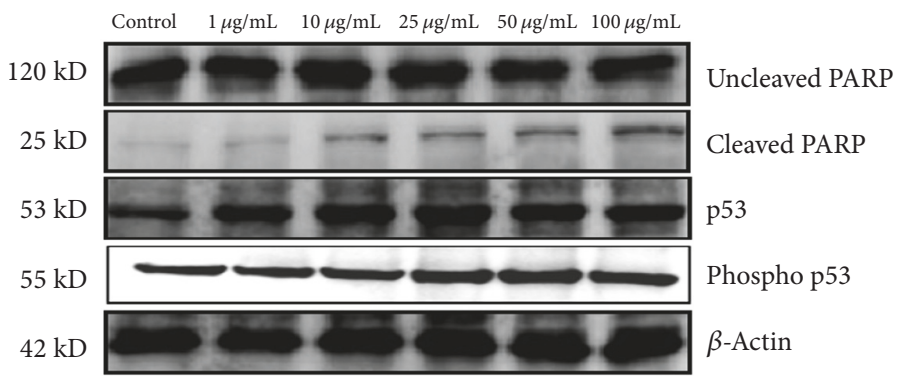

(C)

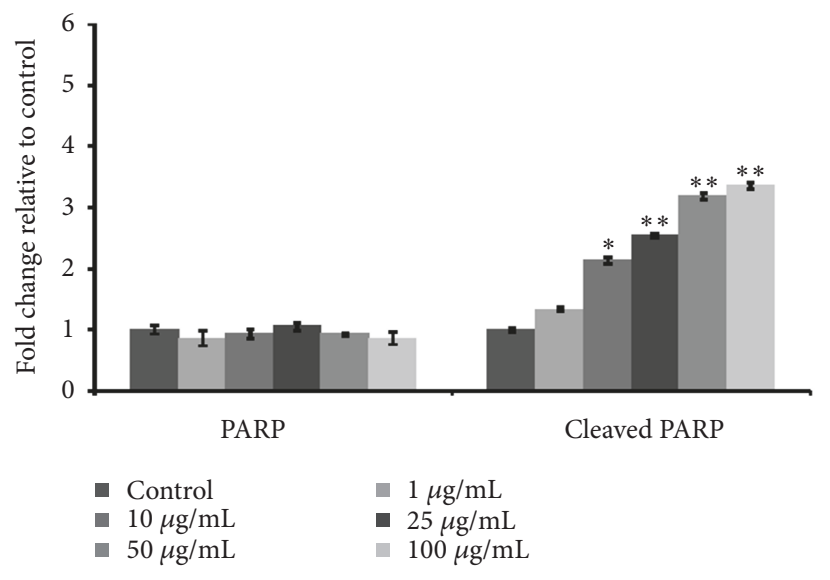

(Cci)

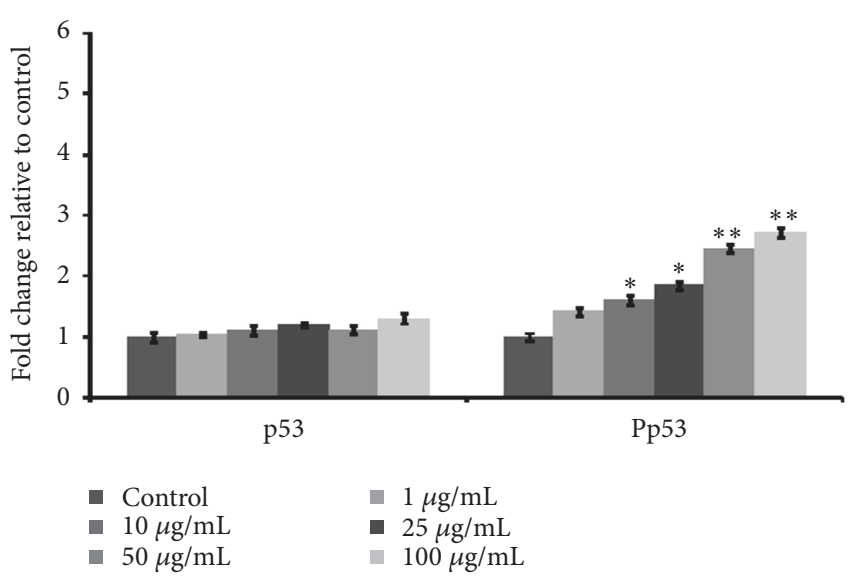

(Ccii)

Figure 9: Dose dependent expression level analysis (A, B, and C) of various apoptotic proteins in A549 cells after $24 \mathrm{~h}$ exposure of CeO2 NPs. Cells exposed to indicated concentration, protein lysate, were collected and assayed by western blotting. $\beta$-actin was used as an internal control. All blots $(\mathrm{A}, \mathrm{B}$, and $\mathrm{C})$ and respective Bar graph $(\mathrm{Aa}, \mathrm{Bb}$, and $\mathrm{Cc}$ ) values (mean $\pm \mathrm{SEM})$ are representative of three independent experiments $(* P<0.05, * * P<0.01$ compared to respective control). 


\section{References}

[1] S. Mittal and A. K. Pandey, "Cerium Oxide Nanoparticles Induced Toxicity in Human Lung Cells: Role of ROS Mediated DNA Damage and Apoptosis," BioMed Research International, vol. 2014, Article ID 891934, 14 pages, 2014. 

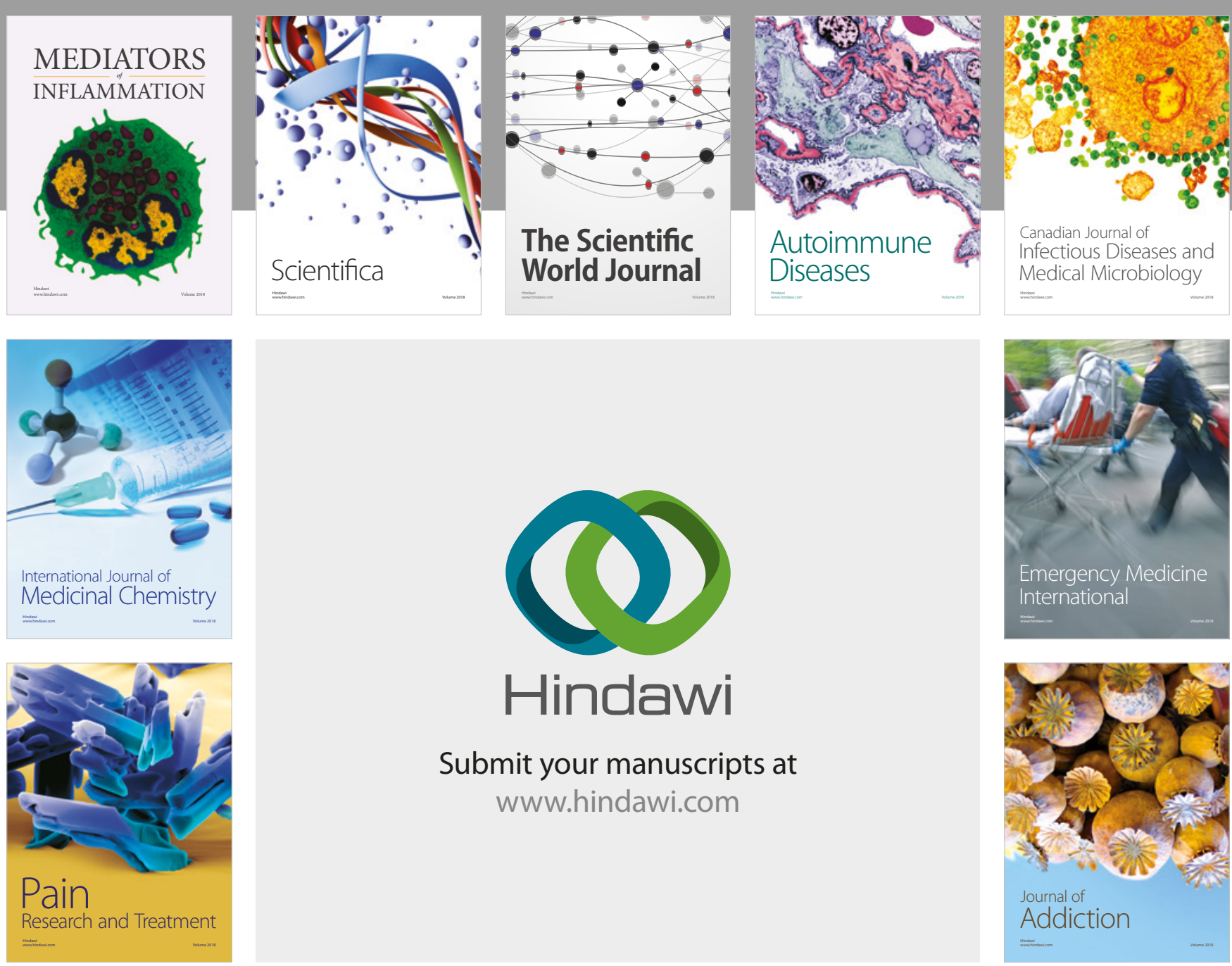

Canadian Journal of
Infectious Diseases and Medical Microbiology

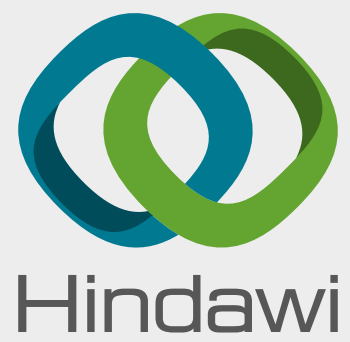

Submit your manuscripts at

www.hindawi.com
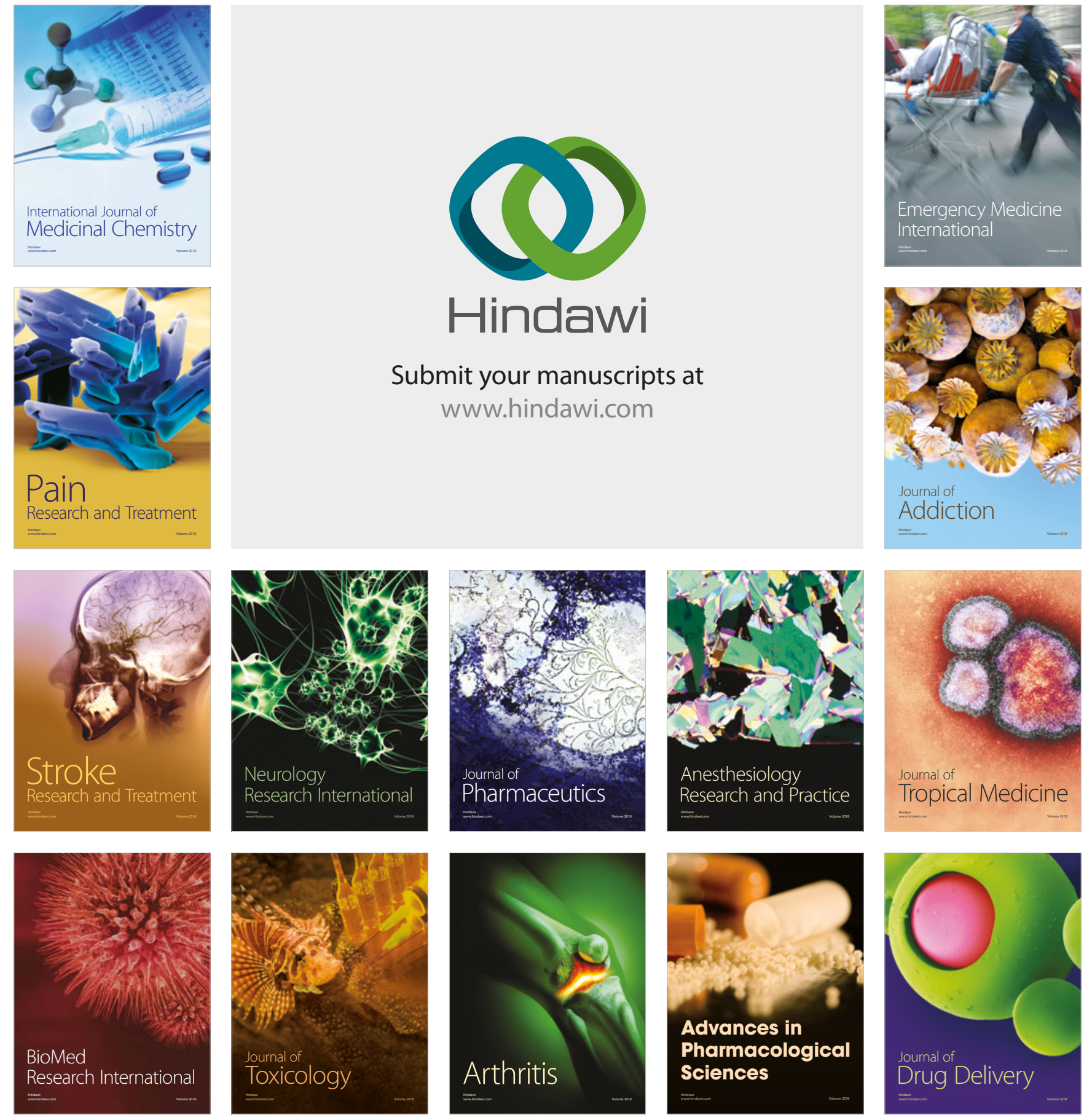